\begin{tabular}{|l|c|c|}
\hline \multicolumn{2}{|c|}{ DJS Vol. 38 (2017) 115-137 } \\
\hline 1969 & Delta Journal of Science & \\
\hline Research Article & Available online at & \\
\hline
\end{tabular}

\title{
Spectroscopic studies on the interaction between thioglycolic acid (TGA)- capped CdTe quantum dots and cyanine dyes
}

\author{
Mostafa F. Abdelbar ${ }^{1}$, Tarek A. Fayed ${ }^{1}$, Talaat M.Meaz ${ }^{2}$ and El- Zeiny M. Ebeid ${ }^{1,3, *}$ \\ 1Chemistry Department, Faculty of Science, Tanta University, Tanta, Egypt \\ 2Physics Department, Faculty of Science, Tanta University, Tanta, Egypt \\ 3Misr University for Science and Technology (MUST), $6^{\text {th }}$ of October City, Egypt
}

\begin{abstract}
Three different particle sizes from cadmium telluride semiconductor quantum dots (CdTe QDs) have been prepared using thioglycolic acid as a capping agent in aqueous media. The photophysical behavior for these particles has been studied in presence of monomethine dyes belong to thiazole orange (TO) family. The aggregation of the cyanine dyes on QDs surface was attributed to the presence of electrostatic attraction between negatively charged thioglycolic capping molecules and the ionic dye. Energy transfer process from CdTe QDs to cyanine dyes was also studied using electronic absorption and steady state emission measurements. The energy transfer parameters such as Stern- Volmer rate constants $K_{s v}$, binding sites $n$, quenching sphere radius " $r$ ", critical energy transfer distance " $\mathrm{R}_{0}$ " and the efficiency of energy transfer $E$, have been calculated. The enhancement in the triplet state emission and absorption for the studied dye in the presence of QDs was expected to play a role in molecular oxygen sensitization and photodynamic therapy (PDT) as well as photovoltaic applications..
\end{abstract}

Key words: CdTe, Quantum dots, Thiazole, Quenching

\section{Introduction:}

Thiazole orange (TO) cyanine dyes, possess many desirable characteristics including high fluorescence efficiency, photochemical stability, and high molar absorption coefficients [1]. The good photoluminescence properties can be used to improve the detection sensitivity, which reduces background interference from intracellular environment or tissues[2]. Moreover, cyanine dyes have higher affinity to tumor than the normal cells which will be widely used in early-stage labeling of cancer cells[ $[\underline{3}, \underline{4}]$.

Cyanine dyes are well known as potential candidates in the field of photodynamic therapy (PDT). The presence of broad emission band in the near IR spectral region leads to singlet oxygen $\left({ }^{1} \mathrm{O}_{2}\right)$ sensitization which causes cytotoxic reactions in the cells. Cyanine sensitizers have been evaluated for PDT in preclinical and in vitro models for treatment of leukemia, lymphoma cells and neuroblastoma where they produced considerable cellular damage [5-8]. Many cyanine dyes possess inherent affinity to tumor cells which will be widely used in early-stage labeling of cancer cells [ $[\underline{]}$. The harvesting of excitation light by cyanine dyes can be improved by using semiconductor quantum dots (QDs) as sensitizers. The combination of semiconductor QDs and PDT photosensitizers enabled the use of an excitation wavelength where the photosensitizer alone does not absorb. Moreover, the spectral properties of the QDs can be adjusted to match those of any PDT photosensitizer by simply adjusting the size of the $\mathrm{QD}[\underline{5}, \underline{6}]$.

QDs present a series of excellent optical properties, including size-dependent tunable photoluminescence. Compared to conventional dyes, confinement of electronic states of quantum dots makes them quite attractive, showing some unique optical properties such as high quantum yield, symmetrical emission spectra, broad-band 
excitation and photostability[ㅇ-13]. The photosensitization of large band gap semiconductors using visible light absorbing dyes has been the subject of active investigation over the past 15 years[14-19].

There are some reports available for the study of interaction between various dyes and QDs [20-24]. This photoinduced interaction between quantum dots, including CdTe QDs, with organic dyes suggests an efficient energy transfer from the excited state of the semiconducting nanoparticles to organic dyes[25].

Recently the nanocrystalline $\mathrm{TiO}_{2}$ solar cells sensitized by benzothiazole type Merocyanines dye $[\underline{26}, \underline{27}]$ showed excellent efficiencies up 5.6\% .The conjugation of such dyes with nanocrystals QDs with the ability of electron transfer by varying the size of QDs to the J aggregate could increase the efficiency more than limited values.

In the present article, three different sizes of CdTe QDs were synthesized from aqueous solutions and were stabilized by using water soluble thioglycolic acid (TGA) as a capping agent. In addition to serving as stabilizer, thioglycolic acid serves to: (i) passivate the surface of QDs and thereby removing the surface traps which lower the photoluminescence efficiency of the quantum dots, (ii) prevent the non-radiative recombination of electrons and holes and (iii) control growth kinetics thereby prevent aggregation via steric hindrance[28, 29]. The capping agent is also a means by which QDs interact with other molecules and their environment [11] through covalent attachments, electrostatic forces and hydrogen bonding[30].

Zhang et al. discussed films in which the nanocrystals had a larger band gap than the Jaggregates [31]. These nanocrystal / J- aggregates films demonstrated $>95 \%$ energy transfer efficiency from the QDs to the J- aggregates, and resulted in enhanced emission intensity of the Jaggregate by a factor of 10 , if the $\mathrm{J}$ - aggregates had larger band gap energy than the nanocrystal, thus the direction of energy transfer is reversed. For the second structure, energy transfer from the Jaggregates donors resulted in a photoluminescence enhancement in the nanocrystal acceptors by about 10 fold enhancement. QD / J- aggregates systems thus find potential applications in biological labeling and fluorescence multiplexing applications [32]. In this article we report the interaction of the three CdTe QDs of different sizes with new monomethine cyanine dye in order to identify the aggregation process within the tunable band gap semiconductor.

\section{Material and methods:}

Cadmium chloride hemi-penta hydrate $\left(\mathrm{CdCl}_{2} .2 .5 \mathrm{H}_{2} \mathrm{O}\right)$, Tellurium (Te) powder, sodium borohydride $\left(\mathrm{NaBH}_{4}\right)$ and thioglycolic acid solution (TGA) $80 \%$, all were of analytical reagent grades (from Sigma Aldrich). The studied cyanine dye, Cy (Scheme 1), has been prepared according to previous literature [33] using microwaveassisted solvent- free synthesis. Thioglycolic acid (TGA)- capped CdTe QDs were synthesized by placing Te powder $(0.0190 \mathrm{~g})$ in a $50 \mathrm{~mL}$ threenecked flask. Excessive sodium borohydride was added under magnetic stirring. Subsequently, the colorless solution of NaHTe was obtained. Then $\mathrm{CdCl}_{2} .2 .5 \mathrm{H}_{2} \mathrm{O}(0.1370 \mathrm{~g})$ and TGA $(80 \mu \mathrm{L})$ were dissolved in $150 \mathrm{~mL}$ ultrapure water, and the $\mathrm{pH}$ was adjusted to11.0 by dropwise addition of $1 \mathrm{~mol}$ $\mathrm{L}^{-1} \mathrm{NaOH}$ solution. The oxygen- free NaHTe solution was injected into cadmium chloride solution under a slow $\mathrm{N}_{2}$ flow over $30 \mathrm{~min}$. CdTe precursors were formed at this stage. The molar ratio of $\mathrm{Cd}^{2+} / \mathrm{TGA} / \mathrm{Te}$ was fixed at 1: 2: 0.25 . The resulting yellow colloidal $\mathrm{CdTe}$ was refluxed under nitrogen flow at $100{ }^{\circ} \mathrm{C}$ for different times to obtain CdTe QDs of different sizes. The aliquots of the reaction solution were pipetted out at different intervals of time $(1,3,5$ and $8 \mathrm{~h})$ for optical measurements. The resulting products were precipitated by isopropanol. The superfluous of TGA and $\mathrm{Cd}^{2+}$ that did not participate in the reaction were removed with centrifugation at 4000 rpm for $5 \mathrm{~min}$. The resultant precipitate was redispersed in water, and re-precipitated by isopropanol for more than two times, then kept at 4 ${ }^{0} \mathrm{C}$ in the dark for further use.

\section{2. Instrumentation}

Fourier-transform infrared (FT-IR) spectra were recorded within wavenumber range 4000$400 / \mathrm{cm}$ by BRUCKER Spectrophotometer using $\mathrm{KBr}$ Pellets. X-ray diffraction (XRD) patterns were recorded at room temperature using GNR, APD 2000 PRO step scan X-ray diffractometer applying $\mathrm{Cu}-\mathrm{K}_{\alpha}$ radiation $(40 \mathrm{kV}, 30 \mathrm{~mA})$. The size of CdTe QDs was calculated using absorption spectra that were recorded using Shimadzu UV-3101PC scanning spectrophotometer. Steady state fluorescence quenching measurements were carried out using Perkin-Elmer LS 50B Spectrofluorometer.

Cyclic voltammograms were measured using an Interface 1000TM Potentiostat (GAMRY 
Instruments). A platinum disk electrode was used as a working electrode while a platinum wire served as a counter electrode. A standard calomel electrode (SCE) electrode was used as a reference electrode. All measurements were carried out in oxygen- free acetonitrile solutions containing tetran-butyl ammonium hexafluorophosphate $\left(\mathrm{TBAPF}_{6}\right)$ as the supporting electrolyte. The scan rate was $50 \mathrm{mV} / \mathrm{s}$.

\section{Results:}

\section{Results and discussion}

\section{1. Characterization of prepared CdTe QDs}

Figures 1a and $\mathrm{b}$ show the typical absorption and normalized luminescence spectra of aliquots taken at different refluxing times of the as- synthesized TGAcapped CdTe QDs. The absorption spectra indicate that CdTe QDs have a wide absorption band with absorption maxima ranging from 475 to $555 \mathrm{~nm}$, similar to those previously reported for thiol stabilized CdTe QDs [29, 30]. CdTe QDs show well resolved sharp and narrow emission peaks ranging from 530 to $605 \mathrm{~nm}$ indicate that QDs possess the desired dispensability, uniformity, and good fluorescence properties. The emission profile remained unchanged after weeks of storage in ambient conditions, suggesting a proper protected surface.

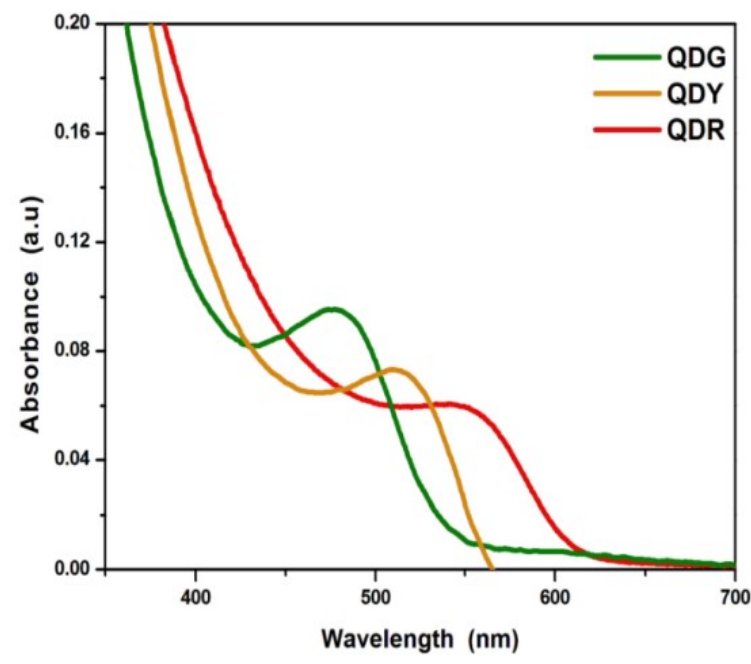

Fig. 1a Absorption spectra of TGA- capped CdTe QDs prepared (from left to right) at 3,6 and $10 \mathrm{~h}$ refluxing times.

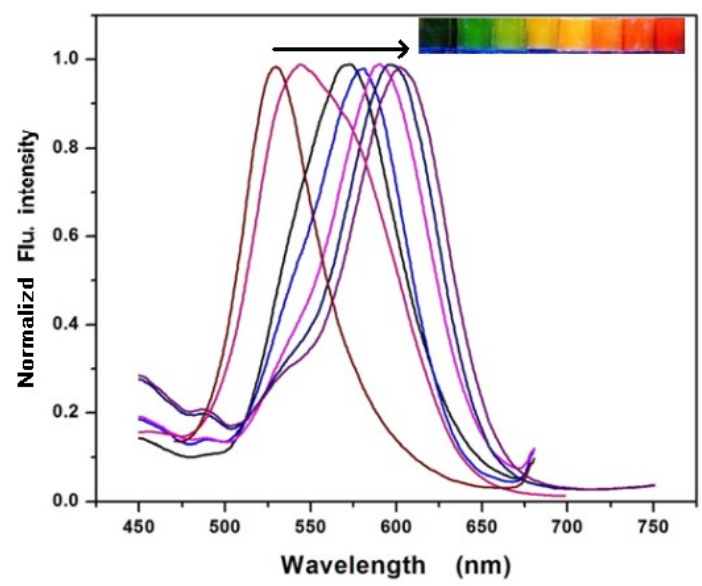

Fig. 1b Normalized emission spectra of TGA- capped CdTe QDs prepared at refluxing times (from left to right)

As the refluxing time increases, a red shift in both absorption and emission bands takes place due to decrease in the kinetic energy of excited electrons and holes following spreading of their wavefunctions [34, 35]. CdTe QDs of three different particle sizes giving emissions in the green, yellow and red regions, of codes QDG, QDY and QDR respectively, have been chosen for energy transfer studies.of 2, 3, 4, 5, 6, 7 and $10 \mathrm{~h}$. Inset is their respective emission colors ( $\lambda$ ex $=365 \mathrm{~nm})$.

The particle sizes of CdTe QDs were determined by applying Eq. (1) [36] and the values were around 1.53, 2.5 and $3.15 \mathrm{~nm}$ corresponding to the first absorption maxima of QDG, QDY and QDR respectively.

$\mathrm{D}=\left(9.8127 \times 10^{-7}\right) \lambda^{3}-(1.7147) \lambda^{2}+(1.0064) \lambda$ $194.84 \quad$ (1)

The concentrations of prepared CdTe QDs were calculated from the UV- Vis. spectral data by applying[37] Lambert Beer's law (Eq. 2):

$$
\mathrm{A}=\varepsilon c \ell
$$

In Eq. (2), $\mathrm{A}$ is the absorbance of first excitonic absorption peak for CdTe QDs, $\mathrm{c}$ is the concentration, $\ell$ is the path length of the radiation beam, and $\varepsilon$ is the molar extinction coefficient of CdTe QDs at the first excitonic absorption peak which was calculated from the formula $\varepsilon=$ $10043(\mathrm{D})^{2,12}$. D is the particle size of the prepared QDs [38].

Fig. 2 shows the XRD pattern of the three CdTe QDs. The XRD patterns of the QDs are considerably broadened due to their very small 
size. The XRD patterns exhibit prominent broad peaks at $2 \theta$ values of $25^{\circ}$ and $44^{\circ}$. The peak at $25^{\circ}$ was shifted to a slight larger angle as the size increases. The peak around $45^{\circ}$ becomes more obvious and a decrease in the peak's broadening occurs as the size increases. The particle size ' $d$ ' was calculated from the XRD data using the Scherrer's equation (3):

$\mathrm{d}=0.9 \lambda / \beta \cos \theta$

Where $\lambda$ is the wavelength of the X-ray radiation, $\beta$ is the full width at half maximum (FWHM) of the XRD peak in radians and $2 \theta$ is the angle of diffraction $\left(24^{0}\right)$. The particle sizes calculated from XRD method were $2.8 \mathrm{~nm}, 3.1 \mathrm{~nm}$ and $4.25 \mathrm{~nm}$.

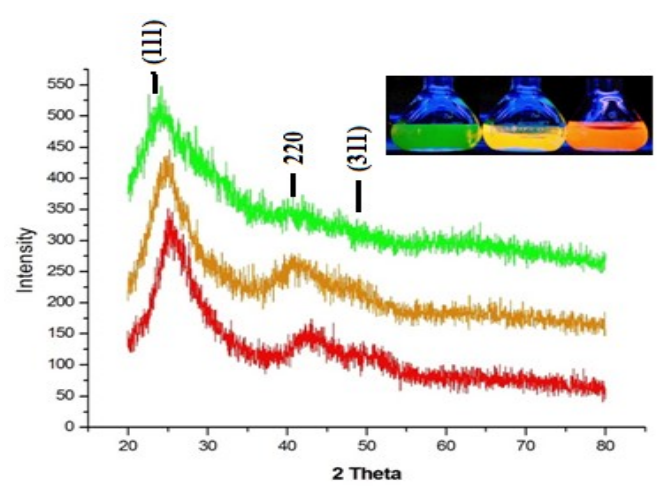

Fig. 2. X- ray diffraction patterns of three synthesized CdTe QDs of green, yellow and red emissions referred to as QDG, QDY and QDR. Inset are their respective emission colors $\left(\lambda_{\mathrm{ex}}=365 \mathrm{~nm}\right)$

FTIR spectra were measured for the as- synthesized TGA- capped CdTe QDs (Figure 3) showing a broad absorption band around $3400 \mathrm{~cm}^{-1}$ that is assigned to $\mathrm{O}-\mathrm{H}$ vibration of the absorbed $\mathrm{H}_{2} \mathrm{O}$. The absorption band due to $\mathrm{S}-\mathrm{H}$ vibration at $2560 \mathrm{~cm}^{-1}$ disappeared upon capping. The characteristic absorption band of $\mathrm{C}=\mathrm{O}$ vibration was shifted from $1700 \mathrm{~cm}^{-1}$ to $1556 \mathrm{~cm}^{-}$ 1. These results strongly suggest that the thiol groups of TGA are linked to QDs surface leaving the hydrophilic carboxylic groups directed outward. This makes the QDs surfaces negatively charged and the QDs become water-soluble.

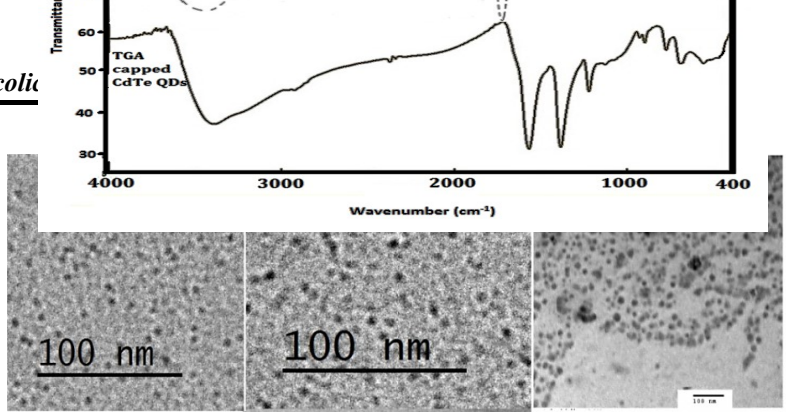

Fig. 3. FTIR spectra of TGA and TGA- capped CdTe QDs

Figure 4 shows the TEM images of CdTe QDs. The TEM images confirm monodispersity with the average size in accordance with the diameters calculated by Xray diffraction and UV- Vis. absorption methods.

Fig. 4. TEM photographs of the as- prepared CdTe QDs

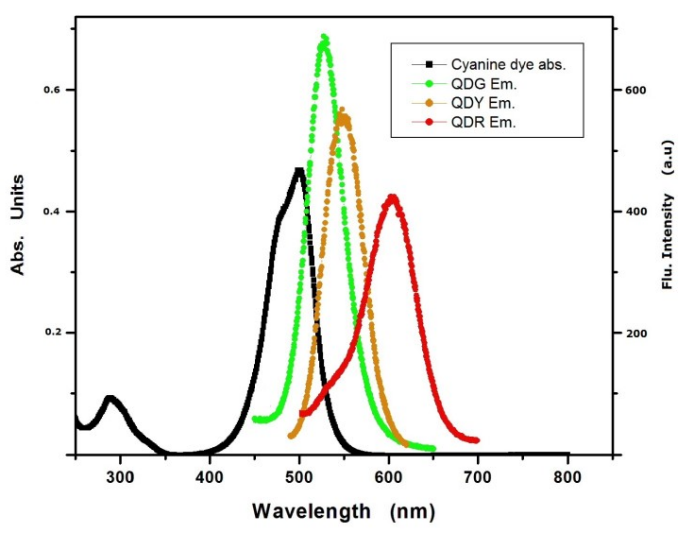

Fig. 5. The overlap between cyanine dye Cy absorption and QDG, QDY and QDR emission spectra.<smiles></smiles>

Scheme 1. Structure of cyanine dye

\section{3. Absorption characteristics of cyanine dye - loaded CdTe QDs}


The absorption spectra of cyanine dye $\mathrm{Cy}$ as well as the emission of CdTe QDs of different sizes are shown in Fig. 5.

Addition of cyanine dye to CdTe QDs solutions results in the build- up of absorption peak around $490 \mathrm{~nm}$ without change in the spectral pattern indicating the absence of ground state complex formation.

\section{4. Fluorescence quenching of colloidal CdTe QDs by cyanine dye}

Figure 5 shows the overlap between the absorption of cyanine dye and the emission of three particle size CdTe QDs. The spectral overlap decreases as the emission

spectrum is red shifted in the sequence: green $>$ yellow $>$ red. Figures 6.b. shows the quenching effect of $\mathrm{Cy}$ on the steady state fluorescence spectrum of CdTe QDs $\left(\lambda_{\text {ex }}=\right.$ $400 \mathrm{~nm})$. In general, static and dynamic quenching can be distinguished by their differing dependence on temperature and viscosity, or by lifetime measurements [39].
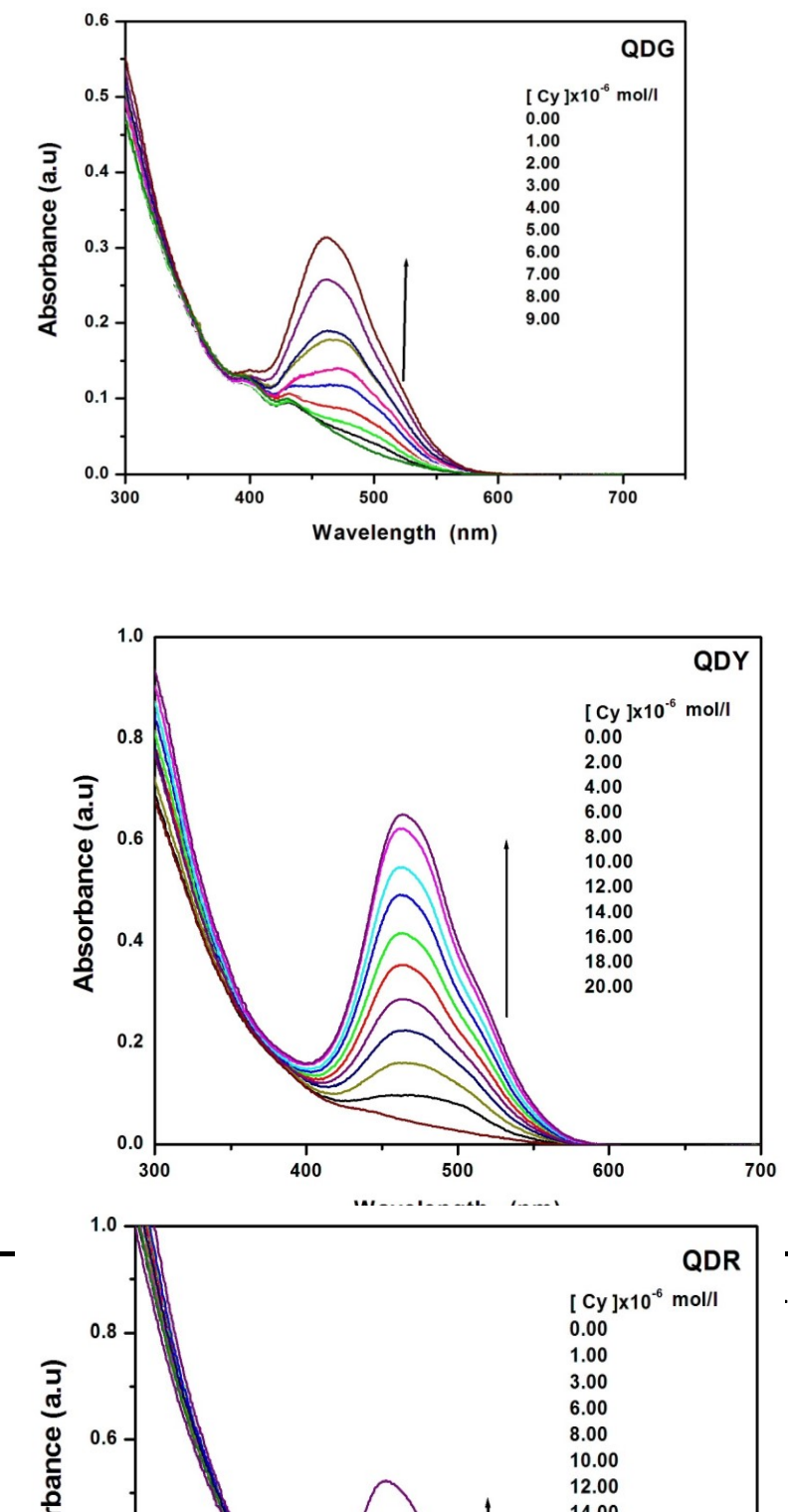

Figure 6 a Effect of Cy concentration variation on the absorption of QDG, QDY and QDR quantum dots $\left(\lambda_{\mathrm{ex}}=\right.$ $400 \mathrm{~nm}$ ).
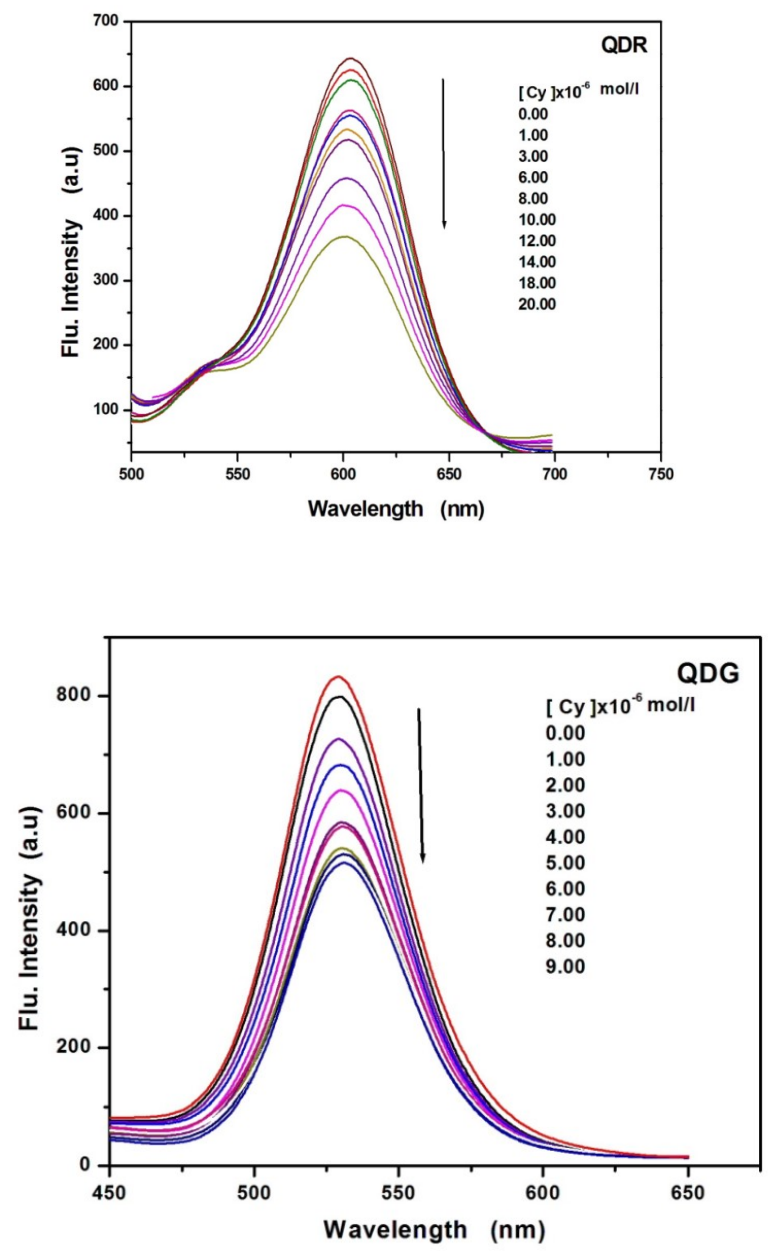

30

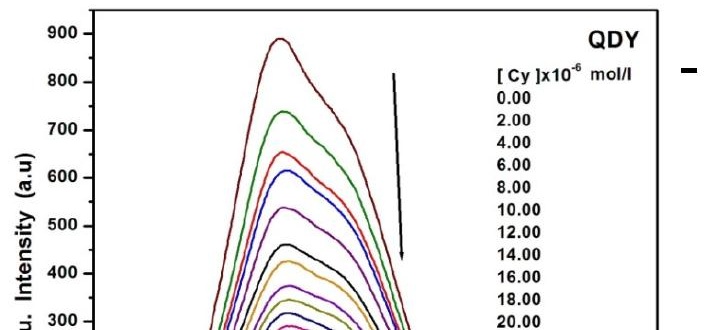


Fig. 6.b. Effect of $\mathrm{Cy}$ concentration variation on the emission of QDG, QDY and QDR quantum dots $\left(\lambda_{\mathrm{ex}}=\right.$ $400 \mathrm{~nm})$.

Collisional quenching is described by the well-known Stern-Volmer equation (Eq. 4):

$\mathrm{I}_{0} / \mathrm{I}=1+\mathrm{K}_{\mathrm{SV}}[\mathrm{Q}]=1+\mathrm{k}_{\mathrm{q}} \tau_{0}[\mathrm{Q}]$.

Where $I_{0}$ and $I$ are the fluorescence intensities in the absence and presence of quencher, respectively, $\mathrm{k}_{\mathrm{q}}$ the bimolecular quenching constant, $\tau_{0}$ the lifetime of the fluorophore in the absence of quencher, [Q] the concentration of quencher and $\mathrm{K}_{\mathrm{SV}}=\mathrm{k}_{\mathrm{q}} \tau_{0}$ is the Stern-Volmer quenching constant. From the plot of $\mathrm{I}_{0} / \mathrm{I}$ vs [Q], the quenching constant was obtained from the slope. Figure 7 shows the Stern-Volmer plots for the quenching of CdTe QDs by cyanine dye Cy. Table 1 shows The Stern-Volmer constants for different sizes of CdTe QDs in presence of $\mathrm{Cy}$ as quencher are listed in table 1.

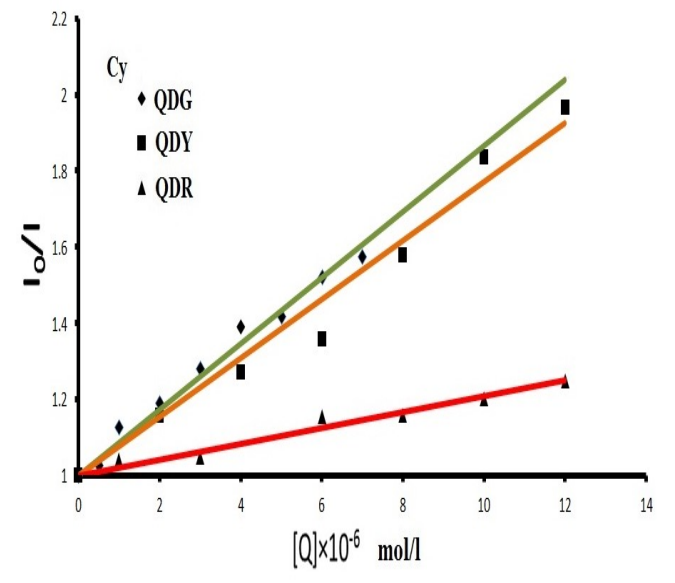

Fig. 7. Stern-Volmer plots for the quenching of QDG, QDY and QDR fluorescence using cyanine dye $\mathrm{Cy}$ as quenchers.
The $\mathrm{K}_{\mathrm{SV}}$ values decrease as the emission of quantum dots is red shifted due to decreasing in overlap between quantum dots emission and cyanine dye absorption. The bimolecular quenching rate constant of CdTe QDs quenching by cyanine dye was calculated as $\mathrm{k}_{\mathrm{q}}=2.97 \times 10^{13}$ $\mathrm{M}^{-1} \mathrm{~s}^{-1}$ using the lifetime of CdTe QDs (QDG) in water as $\tau_{\mathrm{f}}=2.89 \mathrm{~ns}[\underline{40}]$. The upper limit of $\mathrm{k}_{\mathrm{q}}$ expected for a diffusion- controlled process is in the range of $\approx 10^{10} \mathrm{M}^{-1} \mathrm{~s}^{-1}$. [41] For the present system, $\mathrm{k}_{\mathrm{q}}$ values are higher than the diffusioncontrolled rate constants. This suggests that energy transfer mechanisms other than dynamic quenching are prevailing. These include resonance, static and electron transfer quenching mechanisms. The Perrin-model is valid for dipole- dipole energy transfer between donor-acceptor components unable to change spatial position with respect to each other on the timescale of the quenching process. The Perrin relationship $[\underline{42}, \underline{43}]$ is given by Equation 5:

$$
\ln \frac{I_{0}}{I}=V N_{0}[Q]
$$

Where $I_{0}$ and $I$ are emission intensities in the absence and presence of quencher, $\mathrm{V}$ is the volume of the quenching sphere in cubic centimeters, $\mathrm{N}_{\mathrm{o}}$ is Avogadro's number, [Q] is the molar concentration of the quencher. A plot of $\ln \mathrm{I}_{0} / \mathrm{I}$ versus [Q] (Figure 8) demonstrates a linear behavior with a slope of $\mathrm{VN}_{\mathrm{o}}$. The values of $\mathrm{V}$ and $r$ (where $\left.V=(4 / 3) \pi r^{3}\right)$ were calculated and given in Table 1.

\section{Binding constants and binding sites}

When small molecules bind independently to a set of equivalent sites on a macromolecule, the equilibrium between free and bound molecules is given by Equation (6).[44]

$\log \left(\frac{I_{0}-I}{I}\right)=\log K+n \log [Q]$

Where $\mathrm{K}$ is the binding constant to a site and $\mathrm{n}$ is the number of binding sites per cyanine molecule. According to Eq. (6), the binding parameters can be calculated by using the plot of $\log \left(\mathrm{I}_{0}-\mathrm{I}\right) / \mathrm{I}$ against $\log [\mathrm{Q}]$, (see Figure 9 and Table 1). 
The values of binding sites were nearly unity, suggesting that the interaction is mainly between the negative charge of the carboxylate mercaptoacetic group and the positively charged cyanine dye.

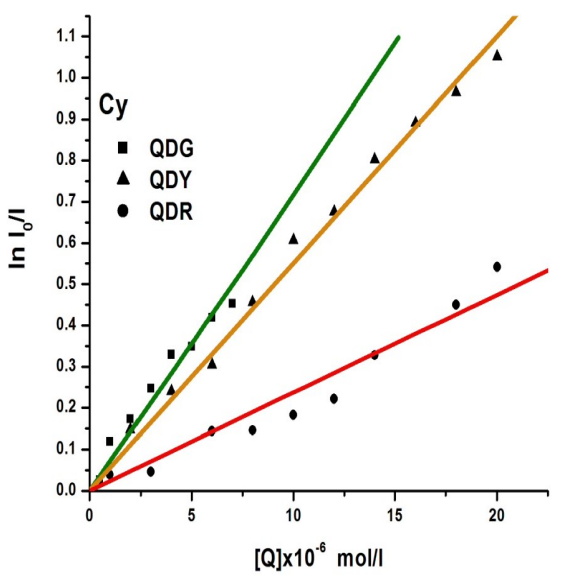

Fig.8 Perrin plots of fluorescence quenching of QDG, QDY and QDR by cyanine dye Cy as quencher.

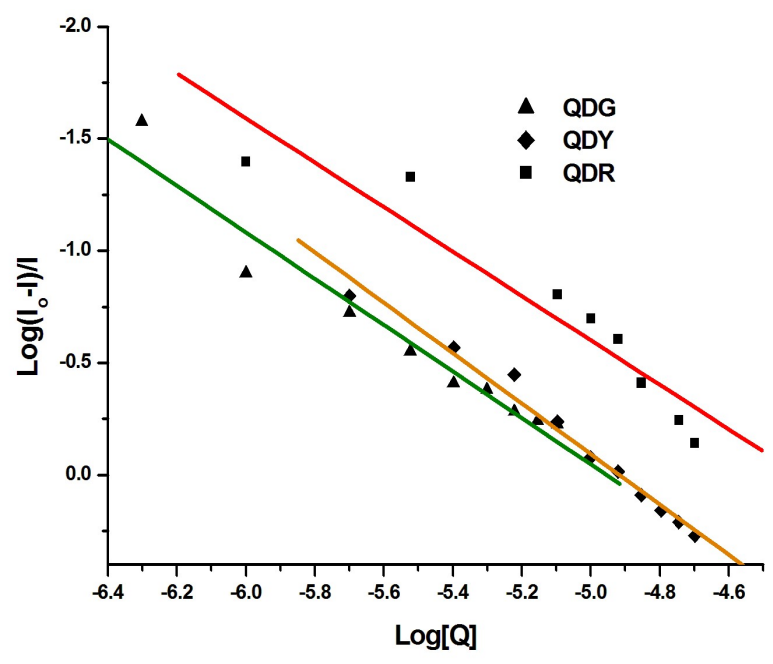

Fig.9. Plots of $\log \left[\left(\mathrm{I}_{0}-\mathrm{I}\right) / \mathrm{I}\right]$ versus $\log [\mathrm{Q}]$ for $\mathrm{QDG}$, QDY and QDR fluorescence quenching by $\mathrm{Cy}$ as quencher.

\begin{tabular}{|lllllll|}
\hline \multicolumn{3}{l}{ QDG } & \multicolumn{2}{l}{ QDY } & \multicolumn{2}{l|}{ QDR } \\
\hline $\mathbf{K}_{\text {sv }} \mathbf{x}$ & \multirow{2}{*}{8.6} & $\mathrm{R}^{2}=$ & \multirow{2}{*}{7.7} & $\mathrm{R}^{2}=$ & 2.0 & $\mathrm{R}^{2}=$ \\
$\mathbf{1 0}^{4}$ & & 0.98 & & 0.98 & 7 & 0.97 \\
\hline $\mathbf{V} \mathbf{x}$ & 11. & $\mathrm{R}^{2}=$ & 9.1 & $\mathrm{R}^{2}=$ & 3.0 & $\mathrm{R}^{2}=$ \\
& 8 & 0.98 & 4 & 0.99 & 9 & 0.97 \\
\hline
\end{tabular}

\begin{tabular}{|lllllll|}
\hline $\begin{array}{l}\mathbf{1 0}^{-17} \\
(\mathbf{c m})\end{array}$ & & & & & & \\
\hline $\mathbf{r}$ & 30. & $\mathrm{R}^{2}=$ & 27. & $\mathrm{R}^{2}=$ & 21. & $\mathrm{R}^{2}=$ \\
$(\mathbf{n m})$ & 44 & 0.98 & 95 & 0.99 & 11 & 0.97 \\
\hline $\mathbf{n}$ & 1.0 & $\mathrm{R}^{2}=$ & 1.1 & $\mathrm{R}^{2}=$ & 0.9 & $\mathrm{R}^{2}=$ \\
& 3 & 0.99 & 2 & 0.99 & 3 & 0.99 \\
\hline $\mathrm{K}^{2} \mathbf{1}$ & 1.3 & $\mathrm{R}^{2}=$ & 3.3 & $\mathrm{R}^{2}=$ & 0.2 & $\mathrm{R}^{2}=$ \\
$\mathbf{0}^{5} \mathbf{M}^{-1}$ & 1 & 0.99 & 7 & 0.99 & 2 & 0.99 \\
\hline
\end{tabular}

Table 1 The Stern-Volmer constants, Quenching sphere $(\mathrm{V})$ values and the radius of quenching sphere ( $r$ ) and the binding constants and numbers of binding sites for QDG, QDY and QDR quantum dots and cyanine dye

\section{Mechanism of quenching}

Two mechanisms are possible for the decrease in fluorescence emission of QDs namely electron transfer and energy transfer. In Figures $6 \mathrm{~b}$ and $7 \mathrm{~b}$ there is a decrease of the donor (CdTe QDs) emission as the acceptor's concentration is increased. For energy transfer to occur there should be an overlap between the emission spectrum of the donor and absorption spectrum of the acceptor. Figure 5 shows the overlap between emission spectrum of CdTe QDs and the absorption spectrum of cyanine dye which indicates a contribution of energy transfer in fluorescence quenching, this contribution decreases by increasing quantum dot size, where the emission is shifted to longer wavelength and the overlap decreases. An energy transfer takes place through direct electrodynamic interaction between the primarily excited molecule and its neighbors [40], which requires that (i) the donor be fluorescent and of sufficiently long lifetime, (ii) the donor molecule's fluorescence emission spectrum overlaps (to some extent) the excitation spectrum of the acceptor molecule and (iii) the distance between the donor and acceptor molecules is small $(1-10 \mathrm{~nm})$ [45]. The energy transfer efficiency (E) could be calculated from equation (7) $[42]$ :

$$
E=\frac{R_{0}^{6}}{R_{0}^{6}+d^{6}}
$$


Where $\mathrm{d}$ is the distance from the donor to acceptor, $\mathrm{R} 0$ is the critical distance at which the efficiency of transfer is $50 \%$ of its origina 1 man.

$$
R_{0}^{6}=8.8 \times 10^{-25} K^{2} n^{-4} \Phi J
$$

Where $\mathrm{K}$ is an orientation factor dependent on the alignment of the donor and acceptor dipoles $\left(\mathrm{K}^{2}=\right.$ $2 / 3$ for random alignment), $n$ is the refractive index of the medium, $\varphi$ is the fluorescence quantum yield of the donor in the absence of the acceptor and $\mathrm{J}$ is the overlap integral between the donor fluorescence and acceptor absorption spectra.

$J(\lambda)=\frac{\int F_{d}(\lambda) \varepsilon_{a}(\lambda) \lambda^{4} d \lambda}{\int F_{d}(\lambda) d \lambda}$

Where $F(\lambda)$ is the corrected fluorescence emission intensity of the donor in the wavelength range $\lambda$ to $(\lambda+\Delta \lambda), \varepsilon(\lambda)$ is the extinction coefficient of the acceptor at $\lambda$. Then the energy transfer efficiency could be determined experimentally from the donor emission in the absence $\left(\mathrm{F}_{0}\right)$ and presence of the acceptor $(\mathrm{F})$, normalized to the same donor concentration [46-48].

$$
E=1-\frac{F}{F_{0}}
$$

The overlap of the absorption spectrum of cyanine and the fluorescence emission spectra of CdTe QDs is shown in Fig. 5. J can be evaluated by integrating for $\lambda=450-575 \mathrm{~nm}$ range. In the present case, $n=1.336$ and $\varphi=0.3,0.37$ and 0.56 . According to Equations (7-10), we calculated the Förster critical distances and the binding distances
QD code
$\mathrm{R}_{0}(\mathrm{~nm})$
d (nm)
$\mathrm{E}$

\begin{tabular}{llll}
\hline QDG & 3.21 & 3.29 & 0.33 \\
QDY & 2.94 & 4.06 & 0.19 \\
QDR & 2.55 & 3.39 & 0.15
\end{tabular}

to cyanine residues on the quantum dots (see Table 2). It can be seen that the data of $R 0$ and $d$ are both within the range of values calculated for similar systems [40].
The calculated R0 values decrease by increasing the size of CdTe and this is attributed to the minimal overlap between the cyanine dye absorption and the emission for larger size CdTe QDs. The efficiency of energy transfer process was at maximum value for the smaller size and its values were significantly influenced by the difference between the critical distance $\mathrm{R}_{0}$ and calculated donor- acceptor separation distance $d$.

The electronic absorption spectrum of cyanine dye shows single absorption peak at $503 \mathrm{~nm}$, this singlet state absorption gives a symmetrical fluorescence peak of emission maximum at 546 $\mathrm{nm}$. The spectral pattern does not alter upon excitation at $480 \mathrm{~nm}$. Another emission broad band in the spectral range $680-900 \mathrm{~nm}$ is also obtained that was attributed to phosphorescence and is a good indication of triplet state formation. Figure 10 shows the synthesized emission enhancement upon increasing the $\mathrm{c}$

oncentration of CdTe QDs as sensitizers.

Table 2 Critical transfer distances $\left(R_{0}\right)$, energy transfer efficiencies (E) and the separation distances (d) distance between CdTe QDs and cyanine dye.

Plateaus are obtained at relative concentration ratios $\approx 1: 10$ for QDG/cyanine, 1:33 for QDY/cyanine and 1:66 for QDR/cyanine systems. The attainment of maximum sensitization occurs at lower cyanine concentrations in case of small size QDG compared with larger size QDY and QDR. This behavior is related to coverage capacity of quantum dots which correlates with sizes.

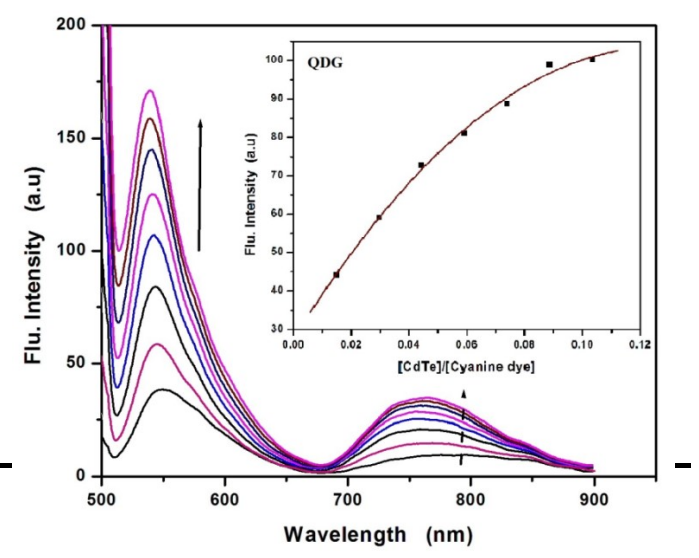



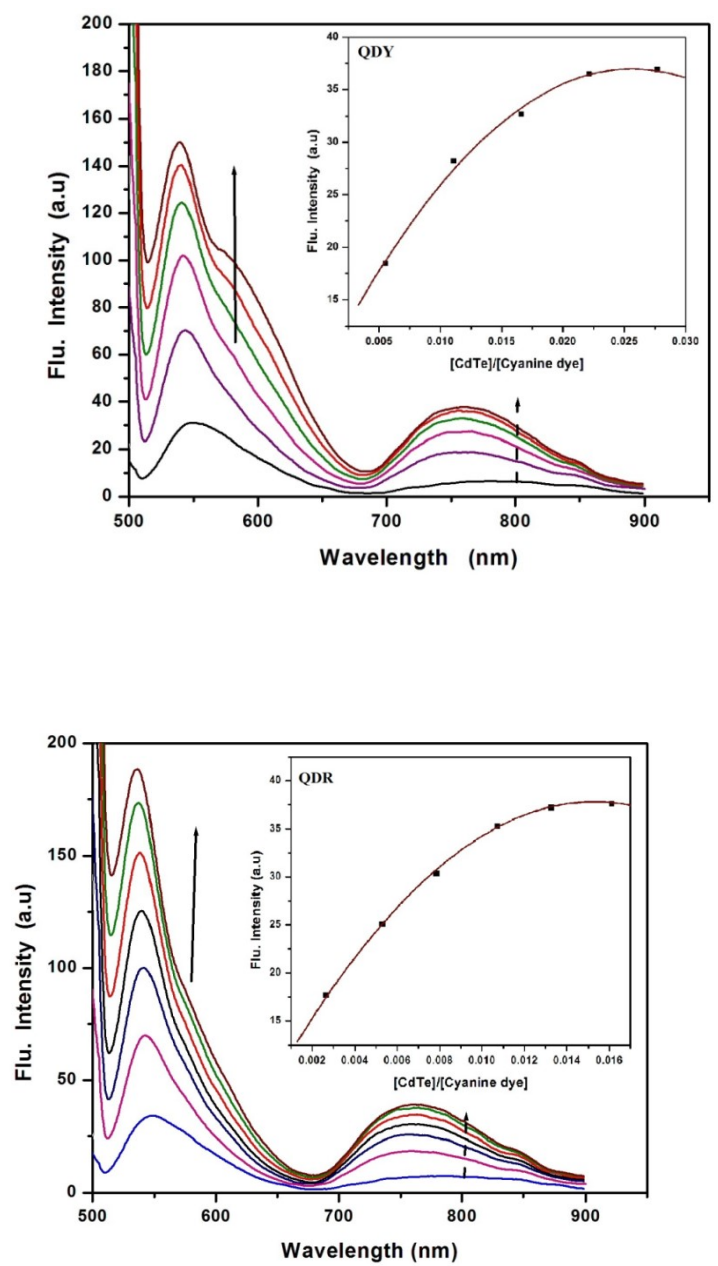

Fig.10. Effect of CdTe QDs addition on cyanine dye emission (Dye concentration $2 \times 10^{-5} \mathrm{M}, \lambda_{\mathrm{ex}}=480 \mathrm{~nm}$ ).

\section{Calculation of free energy changes $\left(\Delta \mathbf{G}_{\mathrm{et}}\right)$ for the electron transfer reactions}

The cyclic voltammograms of CdTe QDs capped with TGA have been reported in the literature[49]. The oxidation potential of CdTe QDs was observed at $0.63 \mathrm{~V}$. It changes slightly with changing the particle size of quantum dots. The thermodynamic feasibility of electron transfer reactions was calculated by employing the RehmWeller expression (11).

$$
\Delta G_{e t}=E_{1 / 2}^{(o x)}-E_{1 / 2}^{r e d}-E_{s}+C
$$

$$
E_{1 / 2}^{(O X)}
$$

donor

Where is the oxidation potential of the

$(0.63 \mathrm{~V}), E_{12}^{\text {sed }}$ is the reduction potential of the acceptor (for cyanine: - $1.0 \mathrm{~V}$ ), the reduction potential for Cy as shown in Figure 11,

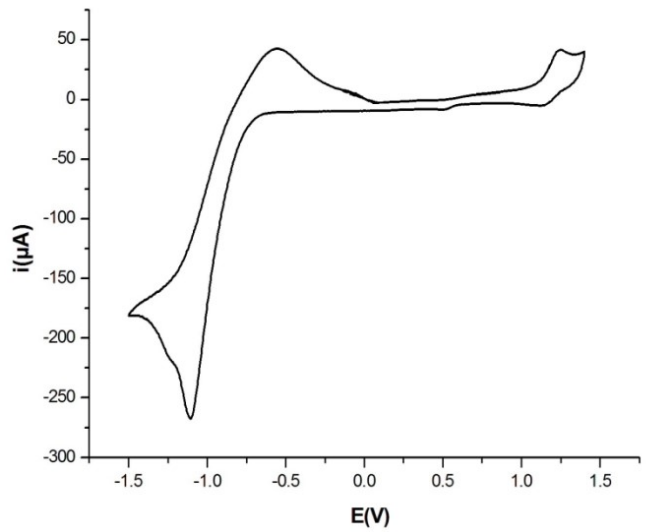

Fig. 11. Cyclic voltammograms of $0.1 \mathrm{mM}$ cyanine dye in (in $\mathrm{CH} 3 \mathrm{CN} / 0.3 \mathrm{M}$ TBABF) recorded using Pt electrode, and $v=50 \mathrm{mV} / \mathrm{s}$.

Es is the excited state energy of the sensitizer (for CdTe QDs 2.33, 2.27 and 2.04 eV for QDG, QDY and QDR respectively, as calculated from the fluorescence spectra and $\mathrm{C}$ is the Coulombic term. Since one of the species is neutral and the solvent used is polar in nature, the Coulombic term in the above expression is neglected [51]. The $\Delta \mathrm{Get}$ values thus calculated for the electron transfer process between CdTe QDs and cyanine dye is negative (- 0.7, - 0.64 and $-0.41 \mathrm{eV})$. Hence, the electron transfer process in the present systems is thermodynamically favorable [52].

\section{Conclusion}

The interaction between three different characterized CdTe quantum dots with monomethine cyanine dye has been studied. Spectral tuning affects energy transfer parameters to cyanine dye where a decrease the Stern- Volmer constants are observed at larger CdTe QD sizes. The efficiency of energy transfer process was also at maximum value for the smaller size and its values were significantly influenced by the difference between the critical distance $\mathrm{R} 0$ and distance separating donor and acceptor $\mathrm{d}$.

For the present system, the calculated quenching rate constants $\mathrm{kq}$ value higher than the diffusioncontrolled rate constants. This suggests that energy 
transfer mechanisms other than dynamic quenching are prevailing. These include resonance, static and electron transfer quenching mechanisms following electrostatic attraction between negatively charged QDs and positively charged cyanine dye. The calculated binding site was nearly unity at low cyanine concentrations. The attainment of maximum sensitization occurs at lower cyanine concentrations in case of small size QDG compared with larger size QDY and QDR. This behavior is related to coverage capacity of quantum dots which correlates with sizes.

The enhancement in the cyanine emission in the Near Infrared region was performed using CdTe QDs as donors. This sensitization becomes of great significance in singlet oxygen sensitization and makes the present system as a potential candidate in the area of photodynamic therapy (PDT). The electron transfer possibility in side with Förster type of energy transfer was thermodynamically favorable.

\section{Acknowledgment}

The authors thank Dr. Hussein H. Alganzory of Benha and Alqassim Universities for providing the cyanine dye.

\section{References}

[1] X. Fei, Y. Gu, Y. Ban, Z. Liu, B. Zhang,Bioorg. Med. Chem., 17 (2009) 585591.

[2] X. Fei, L. Liu, B. Zhang, B. Shi, K. Yao, Progress in Chemistry, 18 (2006) 801-807.

[3] H.S. Rye, S. Yue, D.E. Wemmer, M.A. Quesada, R.P. Haugland, R.A. Mathies, A.N. Glazer,Nucleic Acids Research, 20 (1992) 2803-2812.

[4] S.M. Yarmoluk, D.V. Kryvorotenko, A.O. Balanda, M.Y. Losytskyy, V.B. Kovalska,Dyes and Pigments, 51 (2001) 4149.

[5] A.C. Samia, X. Chen, C. Burda,J. Am. Chem. Soc., 125 (2003) 15736-15737.

[6] A.B. Ormond, H.S. Freeman,Materials, 6 (2013) 817-840.

[7] E. Delaey, F. van Laar, D. De Vos, A. Kamuhabwa, P. Jacobs, P. de Witte,Journal of
Photochemistry and Photobiology B: Biology, 55 (2000) 27-36.

[8] I. Tsujino, K. Miyagi, R.W. Sampson, F. Sieber,Photochemistry and photobiology, 82 (2006) 458.

[9] M. Bruchez, M. Moronne, P. Gin, S. Weiss, A.P. Alivisatos,Science, 281 (1998) 20132016.

[10] W.C.W. Chan, S. Nie ,Science, 281 (1998) 2016-2018.

[11] M. Idowu, E. Lamprecht, T. Nyokong,J. Photochem. Photobiol. A., 198 (2008) 7-12.

[12] F. Wu, J.W. Lewis, D.S. Kliger, J.Z. Zhang,J. Chem. Phys., 118 (2003) 12-16.

[13] X. Zhong, Y. Feng, W. Knoll, M. Han, J. Am. Chem. Soc., 125 (2003) 13559-13563.

[14] A. Hagfeldt, M. Graetzel,Chem. Rev., 95 (1995) 49-68.

[15] C.A. Koval, J.N. Howard,Chem. Rev., 92 (1992) 411-433.

[16] J. Moser, M. Graetzel,J. Am. Chem. Soc., 106 (1984) 6557-6564.

[17] B. O'Regan, M. Graetzel,Nature., 353 (1991) 737.

[18] C.-y. Wang, C.-y. Liu, W.-q. Wang, T. Shen,J. Photochem. Photobiol. A: Chem., 109 (1997) 159-164.

[19] J.Z. Zhang, R.H. O'Neil, T.W. Roberti,J. Chem. Phys., 98 (1994) 3859-3864.

[20] A.R. Clapp, I.L. Medintz, J.M. Mauro, B.R. Fisher, M.G. Bawendi, H. Mattoussi,J. Am. Chem. Soc., 126 (2004) 301-310.

[21] S. Kang, M. Yasuda, H. Miyasaka, H. Hayashi, M. Kawasaki, T. Umeyama, Y. Matano, K. Yoshida, S. Isoda, H. Imahori,ChemSusChem., 1 (2008) 254-261.

[22] I. Potapova, R. Mruk, C. Hübner, R. Zentel, T. Basché, A. Mews,A. Mews, Angew. Chem., 44 (2005) 2437-2440.

[23]E.Zenkevich,T.Blaudeck,M.AbdelMottaleb,F.Cichos,A.Shulga,C.VonBorczysk owski,International J. Photoener., 2006 (2006).

[24] E. Zenkevich, F. Cichos, A. Shulga, E.P. Petrov, T. Blaudeck, C. Von Borczyskowski,J. Phys. Chem. B., 109 (2005) 8679-8692. 
[25] P.r.M. Keane, S.A. Gallagher, L.M. Magno, M.J. Leising, I.P. Clark, G.M. Greetham, M. Towrie, Y.K. Gun'ko, J.M. Kelly, S.J. Quinn,Dal. Trans., 41 (2012) 13159-13166.

[26] Z.-S. Wang, F.-Y. Li, C.-H. Huang,Chem. Commun., (2000) 2063-2064.

[27] K. Sayama, S. Tsukagoshi, K. Hara, Y. Ohga, A. Shinpou, Y. Abe, S. Suga, H. Arakawa,J. Phys. Chem. B, 106 (2002) 1363-1371.

[28] M. Gao, S. Kirstein, H. Möhwald, A.L. Rogach, A. Kornowski, A. Eychmüller, H. Weller, J. Phys. Chem. B., 102 (1998) 83608363.

[29] H. Zhang, Z. Zhou, B. Yang, M. Gao, J. Phys. Chem. B., 107 (2003) 8-13.

[30] A. Samia, S. Dayal, C. Burda,Photochem. Photobiol., 82 (2006) 617-625.

[31] Q. Zhang, T. Atay, J.R. Tischler, M.S. Bradley, V. BuloviÄț, A.V. Nurmikko,Nat.Nanotechnol., 2 (2007) 555559.

[32] T.J. liptay, Spectral properties of semiconductor nanocrystals and their application. $\mathrm{PhD}$ thesis, Massachusetts Institue of technology (2007).

[33] H.H. Alganzory, M.M.H. Arief, M.S. Amine, E.-Z.M. Ebeid, J.Chem. Pharm. Res., 6 (2014).

[34] N. Gaponik, D.V. Talapin, A.L. Rogach, K. Hoppe, E.V. Shevchenko, A. Kornowski, A. Eychmüller, H. Weller,J. Phys. Chem. B., 106 (2002) 7177-7185.

[35] D.V. Talapin, A.L. Rogach, E.V. Shevchenko, A. Kornowski, M. Haase, H. Weller,J. Am. Chem. Soc., 124 (2002) 5782-5790.

[36] J. Li, X. Hong, D. Li, K. Zhao, L. Wang, H. Wang, Z. Du, J. Li, Y. Bai, T. Li,Chem. Commun., (2004) 1740-1741.

[37] Z.A. Peng, X. Peng,J. Am. Chem. Soc., 123 (2001) 183-184.
[38] W.W. Yu, L. Qu, W. Guo, X. Peng,Chem. Mater., 15 (2003) 2854-2860.

[39] W. Guo, J.J. Li, Y.A. Wang, X. Peng,J. Am. Chem. Soc., 125 (2003) 3901-3909.

[40] M.A. Jhonsi, R. Renganathan,J. Coll. Interf. Sci., 344 (2010) 596-602.

[41] X.-Z. Feng, Z. Lin, L.-J. Yang, C. Wang, C.-1. Bai,Talanta, 47 (1998) 1223-1229.

[42] S.R. Bigham, J.L. Coffer,J. Phys. Chem., 96 (1992) 10581-10584.

[43] S. Brown,BOOK REVIEWS, 25 (1980) 7.

[44] B.a.M. Aveline, T. Hasan, R.W. Redmond,J. Photochem. Photobiol. B: Biol., 30 (1995) 161-169.

[45] G.W. Gordon, G. Berry, X.H. Liang, B. Levine, B. Herman,Biophys. J., 74 (1998) 2702-2713.

[46] M. Li, L.G. Reddy, R. Bennett, N.D. Silva, L.R. Jones, D.D. Thomas,Biophys. J., 76 (1999) 2587-2599.

[47] J.R. Lakowicz,Plenum, Principles of Fluorescence Spectroscopy, Press,New York, (1983) 257.

[48] I.X.F.W. R.M. Clegg, B. Herman (Eds.),Wiley, New York, (1996) 179.

[49] S.K. Poznyak, N.P. Osipovich, A. Shavel, D.V. Talapin, M. Gao, A. Eychmüller, N. Gaponik,J. Phys. Chem. B., 109 (2005) 10941100.

[50] D. Rehm, A. Weller,Isr. J. Chem., 8 (1970) 259-271.

[51] P. Ramamurthy, S. Parret, F. Morlet-Savary, J.P. Fouassier, J. Photochem. Photobiol. A. , 83 (1994) 205-209.

[52] S. Nath, H. Pal, D.K. Palit, A.V. Sapre, J.P. Mittal,J. Phys. Chem. A., 102 (1998) 58225830 . 


\section{دراسات طيفية حول التداخل بين نقاط الكم تليريد الكادميوم المحاطه بحمض الثيوجليكولك واصباغ السيانين}

تتميز نقاط الكم (اثباه الموصلات النانومترية) عن الاصباغ العضوية بتغير طيف انبعاثها بتغير الحجم. فى هذه الدراسة تم تحضيروتوصيف ثلاثة حجوم مختلفة من نقاط الكم من تليريد الكادميوم المحاطة بحمض الثيوجليكولك فى الوسط المائى. تم دراسة السلوك الضوئى لهذة المو اد فى وجود صبغة سيانين احادية الميثين تنتمى الى عائلة الثيوزول البرتنقالية

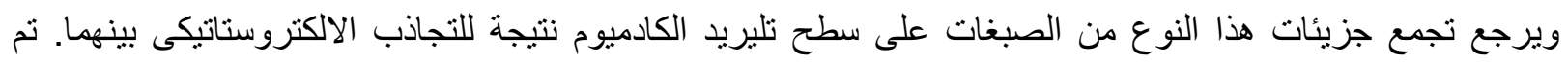
دراسة انتقال الطاقة من تليريد الكادميوم الى صبغة السيانين بقياسات الامتصاص الاكلكترونى وطيف الانبعاث في الحالة

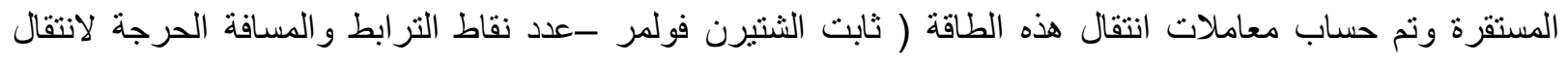
الطاقة ). ونتيجة لانتقال الطاقة تم زيادة طيف الانبعاث الثناثى لهذه الصبغة والذاتى الذاتى يمكن الاستفادة منه فى استثارة

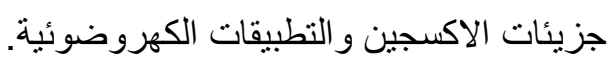

